\title{
(NÃO) SOLUCIONANDO PROBLEMAS CONSTITUCIONAIS: TRANSCONSTITUCIONALISMO ALÉM DE COLISÕES*
}

Marcelo Neves

\section{Da inflação constitucional ao transconstitucionalismo}

A partir do final do século passado, constitucionalistas de diversas tradições teóricas e de países os mais diferentes, vinculados fortemente ao estudo das Constituições estatais, passaram a preocupar-se com os novos desafios de um direito constitucional que ultrapassou as fronteiras dos respectivos Estados e tornou-se diretamente relevante para outras ordens jurídicas, inclusive não estatais. Assim, por exemplo, nos Estados Unidos, Bruce Ackerman, reconhecendo o "provincialismo enfático" da "prática e teoria americana", sublinhou que "nós deveríamos resistir às tentações de um particularismo provinciano" (Ackerman, 1997, pp. 773 e 794). Por sua vez, Mark Tushnet, mais recentemente, em palestra no Instituto de Direito Internacional de Haia, sustentou "a inevitável globalização do direito constitucional” (Tushnet, 2008), esclarecendo que não estava tratando

\footnotetext{
* O presente artigo baseia-se no meu livro Transconstitucionalismo (Neves, 2009; $2^{\text {a }}$ tiragem, 2012). Para o aprofundamento no tema, sugere-se a consulta dessa obra monográfica.
} 
da existência da chamada Constituição global ou internacional, mas sim da globalização do direito constitucional doméstico (Tushnet, 2008, p. 2, nota 7). Do outro lado do Atlântico, Canotilho, com base em Lucas Pires, refere-se à "interconstitucionalidade", restringindo-se, porém, à relação da ordem jurídica da União Europeia com as ordens constitucionais dos seus Estados-membros (Canotilho, 2006, pp. 265 e ss.; Pires, 1997, pp. 101 e ss). Por seu turno, na Alemanha, Pernice, também tendo em vista especialmente a experiência europeia, desenvolveu o modelo de um constitucionalismo de níveis múltiplos (Pernice, 1999; 2002).

Fora do âmbito dos constitucionalistas vinculados à tradição estatal, passou a ser lugar comum a utilização do termo "Constituição" em outras áreas disciplinares, para referir-se a situações as mais diversas: Constituição europeia ${ }^{1}$, Constituição da comunidade internacional ${ }^{2}$, "constituições civis da sociedade mundial” (Teubner, 2003) etc. Dessa

202 maneira, o uso inflacionário do termo tornou-o muito vago, perdendo o seu significado histórico, normativo e funcional. Nesse contexto, "a importância de se chamar Constituição” (Maduro, 2006, pp. 335 e ss.) tomou o primeiro plano, persistindo o equívoco do nominalismo, a que se referiu Ackerman em relação ao constitucionalismo comparado. Daí por que cabe também aqui afirmar: "Diferenças importantes são frequentemente obliteradas em discurso vago que invoca um rótulo comum" (Ackerman, 1997, p. 794) ${ }^{3}$.

Portanto, não se trata aqui de um conceito histórico-universal de Constituição (Canotilho, 1991, p. 59), de acor-

\footnotetext{
1 Entre muitos, Weiler (1999).

2 Cf., p. ex., Fassbender (1998) e Tomuschat (1995, p. 7).

3 Hespanha (2004, pp. 67 e ss.) aponta para o caráter plurívoco da palavra "constituição", que, além de implicar variações históricas no seu significado político-jurídico, ultrapassa a dimensão do mundo cultural, denotando disposições biológicas ou físicas. Mas cabe advertir que um excessivo apego ao significante pode afastar-nos da compreensão do respectivo significado (semântico) e sua função (pragmática) em determinado contexto social ou histórico.
} 
do com o qual vale a fórmula: "nenhum Estado sem Constituição" (Biaggini, 2000, p. 447). Em uma perspectiva de história da Constituição, Koselleck amplia o conceito para incluir "todas as instituições juridicamente reguladas e suas formas de organização, sem as quais uma comunidade social de ação não é politicamente capaz de agir", esclarecendo:

Minha proposta de que a história da Constituição deveria abranger todos os domínios que se caracterizam pela repetibilidade em virtude de regras jurídicas visa a superar, portanto, a fratura entre histórias pré-modernas do direito e histórias modernas da Constituição e, assim, tematizar inclusive fenômenos pós-estatais e, em certa medida, supraestatais, não apenas interestatais, de nossa época (Koselleck, 2006, pp. 370-71) ${ }^{4}$.

Thornhill também propõe um conceito de Constituição "em termos que pode ser aplicado a muitas sociedades em diferentes períodos históricos", embora limitando sua visão de Constituição ao "fato de que ela se refere primariamente às funções dos estados [em geral, não dos estados modernos] e estabelece uma forma legal relativa ao uso do poder pelos Estados ou, no mínimo, por atores que detêm ou utilizam autoridade pública" (Thornhill, 2011, p. 11) . Entretanto, a proposta mais extrema de um conceito histórico universal é oferecida por Teubner nos seguintes termos: "não apenas ubi societas, ibiius, como uma vez disse Grotius, mas sim ubi societas, ibi constitutio" (Teubner, 2012, p. 65$)^{6}$.

\footnotetext{
4 Parece-me que Koselleck também cai em anacronismo ao ampliar o conceito de Constituição para abarcar instituições e experiências muito diversas historicamente.

5 Diferentemente do que sugere Thornhill, entendo que essa discussão não deve ser confundida com a questão referente à existência ou não de "constituições formalmente escritas" (Thornhill, 2011, pp. 9-10).

6 Trad. ingl., 2012, p. 35 - a referência a Grotius só aparece na tradução.
} 
Normalmente, o conceito histórico-universal de Constituição apresenta-se no plano empírico, para apontar que em toda sociedade ou Estado há relações estruturais básicas de poder, determinantes também das formas jurídicas. Conforme essa concepção, que se encontra em autores tão díspares como Engels, Lassale e Weber ${ }^{7}$, não se pode excluir a presença de uma Constituição de qualquer ordem social, inclusive das sociedades arcaicas, pois, também nelas, haveria estruturas básicas do "poder difuso" (Burdeau, 1949, pp. 249-51). Mas o conceito histórico-universal apresenta-se também na concepção da Constituição em sentido material como conjunto de normas jurídico-positivas supremas (Kelsen, 1960, pp. 228-30 [trad. bras., 2006, pp. 247-49]; 1946, pp. 124-25 [trad. bras., 2005, pp. 182-83]; 1925, pp. 251-53), pois um núcleo normativo supremo pode ser detectado em qualquer ordem jurídica. Um conceito desse tipo poderia excluir ordens jurídicas primitivas, na medida

204 em que nelas faltariam as normas secundárias de organização, sobretudo a regra última de reconhecimento, que atuaria como uma Constituição em sentido material; não obstante, para todo e qualquer Estado, haveria uma Constituição (regras últimas de reconhecimento) ${ }^{8}$. Por fim, também pode ter um caráter histórico-universal o conceito culturalista, seja quando define a Constituição do Estado como "dialética" da normalidade política e normatividade jurídica (Heller, 1934, pp. 249 e ss. [trad. bras., 1968, pp. 295 e ss.]) ou quando a concebe como "processo de integração" (Smend, 1968 [1928], espec. pp. 136 e ss. e pp. 189-91), pois tal "dialética" e tal "processo" são encontráveis em qualquer tipo de Estado, inclusive no pré-moderno, no absolutista e

7 Cf. Engels (1988 [1844], espec. pp. 572 e ss.); Lassalle (1987 [1862], p. 130); Weber (1985 [1922], p. 27 [trad. bras., 2004, vol. I, p. 35]).

8 Cf. Hart (1994, pp. 91-123 e ss., espec. p. 107 [trad. port., 2001, pp. 101-35, espec. pp. 118 e ss.]). Hart (1994, p. 60 [trad. bras., 2001, p. 69]) fala também de "questões constitucionais" em relação às regras secundárias de alteração. 
no autoritário. A análise da especificidade do sentido e da função da Constituição, como uma das "poucas aquisições da civilização moderna" que são "o resultado de um planejamento intencional” (Luhmann, 1990a, p. 176), fica prejudicada com esses conceitos de perfil histórico-universal ${ }^{9}$.

Afasto-me dessa tendência de sempre identificar a existência de uma nova Constituição quando surge uma ordem, instituição ou organização jurídica na sociedade contemporânea. Partindo da sólida noção de que a Constituição em sentido estritamente moderno vincula-se ao constitucionalismo que resultou das revoluções liberais dos fins do século XVIII na França e nos Estados Unidos e, de maneira atípica, da evolução político-jurídica britânica, procurarei determinar quais problemas se apresentaram como condição de possibilidade histórica do surgimento do Estado constitucional. Fixados os problemas, cabe indagar qual foi a resposta funcional e normativa que se pretendeu consubstanciar nas constituições do Estado moderno. É exatamente essa relação entre problema e solução de problema que vai viabilizar a fixação do conceito de Constituição do constitucionalismo.

Dois problemas foram fundamentais para o surgimento da Constituição em sentido moderno: de um lado, a emergência, em uma sociedade com crescente complexidade sistêmica e heterogeneidade social, das exigências de direitos fundamentais ou humanos; de outro, associada a isso, a questão organizacional da limitação e do controle interno e externo do poder (inclusive mediante a participação dos governados nos procedimentos, sobretudo nos de determi-

9 Cf. Luhmann (1990a, p. 212). Ao contrário do que afirma Thornhill (2011, p. 9), Luhmann não aceitou "latitude na definição de Constituição", antes propôs um conceito muito estrito de Constituição: "Minha tese será que o conceito de Constituição, ao contrário da primeira impressão, reage a uma diferenciação entre direito e política e, de fato, dito fortemente, à diferenciação plena desses dois sistemas funcionais e à necessidade de conexão que daí resulta" (Luhmann, 1990a, pp. 179-80). 
nação da composição de órgão de governo), que também se relacionava com a questão da crescente especialização das funções, condição de maior eficiência do poder estatal. O fato é que, mais recentemente, com a maior integração da sociedade mundial, esses problemas tornaram-se insuscetíveis de serem tratados por uma única ordem jurídica estatal no âmbito do respectivo território. Cada vez mais, problemas de direitos humanos ou fundamentais e de controle e limitação do poder tornam-se concomitantemente relevantes para mais de uma ordem jurídica, muitas vezes não estatais, que são chamadas ou instadas a oferecer respostas para a sua solução. Isso implica uma relação transversal permanente entre ordens jurídicas em torno de problemas constitucionais comuns. O direito constitucional, nesse sentido, embora tenha a sua base originária no Estado, dele se emancipa, não precisamente porque surgiu uma multidão de novas Constituições, mas sim tendo em vista que outras 206 ordens jurídicas estão envolvidas diretamente na solução dos problemas constitucionais básicos, prevalecendo, em muitos casos, contra a orientação das respectivas ordens estatais. Além do mais, surgem permanentemente relações diretas entre Estados para tratar de problemas constitucionais comuns. A exceção, nos dois casos, passou a ser a regra.

Em face dessa situação, introduzo o conceito de transconstitucionalismo. Por um lado, o transconstitucionalismo não se confunde com um mero transjuridicismo, que pode ser observado inclusive na relação entre ordens jurídicas no pluralismo medieval, sobretudo entre direito canônico (e romano), direito urbano, direito real e direito feudal ${ }^{10}$, pois, na experiência medieval, não se tratava de problemas constitucionais no sentido moderno, ou seja, nem de questões de direitos fundamentais nem de limitação e controle jurídico-positivo do poder, muito menos de pretensões

${ }^{10}$ Cf. Berman (1983, figura 2, pp. 522-26 [trad. bras., 2006, pp. 646-50]). 
diversas de autofundamentação do direito (em última instância e em geral, o direito tinha um fundamento sacro ${ }^{11}$ ).

Por outro lado, não se trata de constitucionalismo internacional, transnacional, supranacional, estatal ou local. $\mathrm{O}$ conceito aponta exatamente para o desenvolvimento de problemas jurídicos que perpassam os diversos tipos de ordens jurídicas. Um problema transconstitucional implica uma questão que poderá envolver tribunais estatais, internacionais, supranacionais e transnacionais (arbitrais), assim como instituições jurídicas locais nativas, na busca de sua solução. Para tratar do transconstitucionalismo, recorro ao conceito de "razão transversal" de Wolfgang Welsch (1996; 2002, pp. 295-318), mas me afasto um tanto desse ambicioso conceito, para analisar os limites e possibilidades da existência de "racionalidades transversais" ("pontes de transição") tanto entre o sistema jurídico e outros sistemas sociais (constituições transversais) quanto entre ordens jurídicas no interior do direito como sistema funcional da sociedade mundial ${ }^{12}$.

Além disso, ao tratar do transconstitucionalismo, não o considerarei apenas como exigência funcional e pretensão normativa de uma racionalidade transversal entre ordens jurídicas, mas também levarei em consideração, empiricamente, os aspectos negativos dos entrelaçamentos transconstitucionais, inclusive em caso de o problema envolver situações de ordens ou práticas anticonstitucionais, ou seja, contrárias à proteção dos direitos humanos e fundamentais, assim como ao controle e limitação do poder. Da mesma maneira, serão discutidas práticas anticonstitucionais presentes em ordens de Estados tipicamente constitucionais ${ }^{13}$. Nesse sentido, cabe distinguir o transconstitucionalismo (gênero), que inclui relações entre ordens constitucionais e anticonstitucionais, do interconstitucionalismo (espécie),

${ }^{11}$ Cf. Neves (2009, pp. 8-10 e 16, nota 63 [trad. ingl., 2013, pp. 9-11 e 14, nota 63]).

${ }^{12}$ Cf. Neves (2009, pp. 38 e ss. [trad. ingl., 2013, pp. 28 e ss.]).

${ }^{13}$ Cf., p. ex., Scheppele (2006), Roach (2006) e Gross (2006). 
que só comporta relações entre ordens jurídicas que satisfazem as exigências constitucionalistas.

O transconstitucionalismo não toma uma única ordem jurídica ou um tipo determinado de ordem como ponto de partida ou ultima ratio. Rejeita tanto o estatalismo quanto o internacionalismo, o supranacionalismo, o transnacionalismo e o localismo como espaço de solução privilegiado dos problemas constitucionais. Aponta, antes, para a necessidade de construção de "pontes de transição", da promoção de "conversações constitucionais", do fortalecimento de entrelaçamentos constitucionais entre as diversas ordens jurídicas: estatais, internacionais, transnacionais, supranacionais e locais. O modelo transconstitucional rompe com o dilema "monismo/pluralismo". A pluralidade de ordens jurídicas implica, na perspectiva do transconstitucionalismo, a relação complementar entre identidade e alteridade. As ordens envolvidas na solução do problema constitucional específico, 208 no plano de sua própria autofundamentação, reconstroem continuamente sua identidade mediante o entrelaçamento transconstitucional com a(s) outra(s): a identidade é rearticulada a partir da alteridade. Daí por que, em vez da busca de uma Constituição hercúlea, o transconstitucionalismo aponta para a necessidade de enfretamento dos problemas-hidra constitucionais mediante a articulação de observações recíprocas entre as diversas ordens jurídicas da sociedade mundial.

\section{Da fragmentação jurídica e constitucional ao transconstitucionalismo}

O modelo transconstitucional não compartilha irrestritamente a ideia tão amplamente difundida de fragmentação do direito, que ganhou contornos sistêmico-teoréticos precisos especialmente na obra de Teubner e seus discípulos ${ }^{14}$.

\footnotetext{
${ }^{14}$ Cf. Teubner (2012 [trad. ingl., 2012]; 2006, pp. 185 e ss.); Fischer-Lescano e Teubner (2006; 2007); Fischer-Lescano (2005, pp. 187 e ss.).
} 
Considerando que a teoria dos sistemas adota conceitos originários da biologia, como diferenciação, evolução, coevolução, autopoiese, acoplamento estrutural, entre outros ${ }^{15}$, não no sentido de analogia, mas sim de generalização, cabe arguir, com uma certa ironia, que, nesse contexto, a noção de teórico-social ou sociológico-jurídico de fragmentação deveria ser relacionada a suas raízes na concepção biológica de fragmentação como processo reprodutivo. Se entendemos assim, esbarramos em problemas que a teoria social ou jurídica da fragmentação da sociedade ou do direito não teria enfrentado adequadamente. Aqui, cabe referência à "red queen hypotheses", baseada na seguinte afirmação da RainhaVermelha para Alice, na obra Through the looking glass, de Lewis Carroll: "Como você vê, nesse mundo é preciso correr o máximo que puder para ficar no mesmo lugar"16 ("Now, here, you see, it takes all the running you can do, to keep in the same place" (Carroll, 1939 [1872], p. 166). Formulada inicialmente por Leigh Van Valen (1974, pp. 90 e ss.), essa hipótese aponta, especialmente na variável desenvolvida por William D. Hamilton (1980; Hamilton, Henderson e Moran, 1981), para o papel da reprodução sexual na promoção de variabilidade genética e maior capacidade de seleção em relação aos elementos e fatores do ambiente, especialmente em relação aos parasitas ${ }^{17}$. A fragmentação, ao contrário, como forma típica de reprodução assexual, importa limitada variação genética, frágil capacidade de seleção e de reposta às adversidades do ambiente, o que significa poucas alternativas evolutivas. Uma das vantagens das espécies sexuais em relação às assexuais está associada a "abundante polimorfismo" (Riddley, 2003, p. 84) ${ }^{18}$, implicando que as espécies sexuais têm maior capa-

\footnotetext{
${ }^{15}$ Cf. Teubner (1989, espec. pp. 66 e ss. [trad. ingl., 1993, espec. pp. 51 e ss.]).

${ }^{16}$ Tradução do autor.

17 A respeito, ver a exposição abrangente de Riddley (2003). Com algumas restrições, ver Neiman e Koskella (2009).

18 Cf. Hamilton (1980, espec. p. 283) e Hamilton, Henderson e Moran (1981,
} 
cidade de responder às adversidades do ambiente ${ }^{19}$. Apesar das divergências, a "red queen hypotheses" parece já encontrar elementos precursores na obra de Darwin, o qual, embora considerando que as espécies assexuais não são totalmente incompatíveis com a evolução (Darwin, 1971 [1872], p. 24), enfatizava, além daquela hipótese, que, mesmo na reprodução sexual, a autofertilização envolve uma limitada ou implausível capacidade evolutiva, nos seguintes termos, afirmando ser "uma lei geral da natureza que nenhum ser orgânico fertiliza a si mesmo para uma perpetuidade de gerações; mas que o cruzamento com outro indivíduo é ocasionalmente - talvez em intervalos longos de tempo - indispensável” (Darwin, 1971 [1872], p. 95). E apontava inclusive para a desvantagem dos cruzamentos próximos:

[...] eu coletei um amplo conjunto de fatos e fiz muitos experimentos mostrando que [...], com animais e plantas, um cruzamento entre diferentes variedades, ou entre indivíduos da mesma variedade, mas de outra linhagem, dá vigor e fertilidade à prole; e, por outro lado, que cruzamento próximo diminui vigor e fertilidade (Darwin, 1971 [1872], p. 95).

espec. p. 66), que enfatizaram, porém, que pretendiam ir além da questão do polimofismo, para concentrarem o seu foco no problema do sexo (p. 65). A questão da importância do polimorfismo remonta a Haldane (1990 [1949]), que também advertia para "o perigo da homogeneidade" (329 [6]).

${ }^{19} \mathrm{Na}$ linguagem metafórica de Ridley, "as espécies sexuais podem recorrer a um tipo de biblioteca de fechaduras que não está disponível às espécies assexuais" ("Sexual species can call on a sort of library of locks that is unavailable to asexual species" [Riddley, 2003, p. 72]). De acordo com Hamilton, Axelrod e Tanese (1990, p. 3568), "o sucesso do sexo aumenta como número de loci envolvidos na defesa contra parasitas". Eles afirmam: "A essência do sexo em nossa teoria é que ele armazena genes que estão ruins, mas oferecem promessa para reutilização. Ele os prova continuamente em combinação, à espera do momento em que o foco de desvantagem mudou para outro lugar. Quando isso acontece, os genótipos que comportem esses genes espalham-se mediante exitosa reprodução, tornando-se, simultaneamente, reservas para outros genes ruins e, assim, progressivamente, em sucessão contínua" (Hamilton, Axelrod e Tanese,1990, p. 3569). 
Dessa maneira, já se assinalava a importância da sexualidade entre seres geneticamente diversos para a evolução das espécies.

Estou consciente do perigo de uma leitura conservadora da "red queen hypotheses" se for transportada de forma sociobiologista para o campo das ciências sociais, assim como do fato de que a teoria dos sistemas sociais desenvolvida a partir de Luhmann afirma, nos termos da concepção dos fundadores da sociologia, radicalizando-a, a "emergência de cima" na relação entre sistemas sociais, psíquicos e biológicos (Luhmann, 1987 [1984], pp. 43-44 [trad. esp., 1998, pp. 45-46]; Teubner, 1989, pp. 40-41 [trad. ingl., 1993, pp. 29-30] $)^{20}$. Aqui caberia uma releitura socialmente adequada. Parece-me oportuno considerar que a mera fragmentação é incompatível com transformações adequadas dos sistemas sociais em face do seu ambiente sempre mais complexo. Os problemas se renovam e os sistemas sociais ou ordens jurídicas precisam construir não apenas acoplamentos estruturais com seu ambiente, mas também construir novas "pontes de transição" com outras ordens jurídicas ou sistemas sociais, para que sejam aptos a articular-se em face da flutuação permanente dos fatores dos respectivos ambientes. A simples fragmentação não oferece caminhos de solução ao novos problemas que emergem nos processos de transformação social contínua. Sem o desenvolvimento de "polimorfismo" mediante "pontes de transição" flexíveis, os sistemas ou ordens jurídicas seriam paralisados na sua reprodução, sendo levados à "morte" pelo cristal, ou seja, cairiam na hiperintegração por excesso de redundância ${ }^{21}$. Em outras palavras, a construção de

\footnotetext{
${ }^{20}$ Nem por isso Luhmann e Teubner deixaram de recorrer a conceitos da teoria biológica de Maturana e Varela (1980, pp. 107-11; 1987, pp. 196 e ss.), que partem da "emergência de baixo", considerando os seres vivos como componentes dos sistemas sociais.

${ }^{21}$ Uso aqui a metáfora de Atlan (1979, p. 281), ao distinguir, no limite, entre "a
} 
eclusas, especialmente no concernente ao direito, depende, paradoxalmente, de conexões transversais entre sistemas sociais e ordens jurídicas. É por isso que a orientação funcional da relação entre problema e solução de problema deve considerar como ocorre a tessitura dos fragmentos em uma ordem diferenciada de comunicação. Para isso, é necessária uma certa desintegração interna, que é indissociável do incremento de flexibilidade ou variedade para fora, dependente de intercruzamentos promotores da renovação permanente da identidade em vista da alteridade. Isso significa, enfim, que os problemas de colisão não são enfrentados ou solucionados a cada passo no nível da mera fragmentação ou dos simples fragmentos, mas sim por via de pontes construídas transversalmente entre as unidade constitutivas de uma ordem diferenciada de comunicação em constante transformação.

Do ponto de vista do sistema jurídico, essa situação é 212 ainda mais patente se considerarmos que as diversas ordens jurídicas do sistema jurídico mundial utilizam o mesmo código binário de comunicação (lícito/ilícito), mas têm estruturas e níveis de autonomia totalmente diversos. A esse propósito, cabe apontar para um outro problema da concepção de pluralismo jurídico na sociedade mundial. O modelo heterárquico do mainstream sistêmico parte de conceitos quase apriorístico de autonomia ou autopoiese de regimes fragmentados supostamente constitucionais, em uma dinâmica plena de diferenciação funcional ${ }^{22}$. Não observa, empiricamente, que diversas formas e ordens jurí-

morte por rigidez, a do cristal, do mineral, e a morte por decomposição, a da fumaça”, ou seja, entre excesso de redundância e excesso de variedade.

22 "Conhecidamente, a globalização significa sobretudo que a dinâmica da diferenciação funcional, que, historicamente, realizou-se primeiramente nos estados nacionais da Europa e da América do Norte, alcança, agora, todo o globo terrestre" (Teubner, 2012, p. 72 [trad. ingl., 2012, p. 42]; cf. também pp. 119-20 [trad. ingl., pp. 74-75], a respeito da relação entre Constituição e autonomia do sistema jurídico no plano do pluralismo constitucional global). 
dicas do sistema jurídico mundial não dispõem de um mínimo de autonomia, muito menos de autonomia constitucional, não só por serem instrumentos (direito como meio) da política (totalitarismo e autoritarismo) ou da economia (formas de direito orientadas quase exclusivamente à eficiência do mercado), mas também por não disporem sequer das chamadas regras secundárias de organização, como o direitos dos povos indígenas e tribais. Todas elas, porém, encontram-se expostas aos mesmos problemas constitucionais. Quando o modelo dominante de pluralismo constitucional enfrenta o problema de ordens jurídicas tribais, limita-se a considerar, especialmente na perspectiva do direito de propriedade intelectual, como essas ordens serão compatibilizadas com o modelo do direito de patente ${ }^{23}$. Não se leva a sério a observação irônica (alguns dizem cínica) de Luhmann de que o modelo de diferenciação do direito talvez seja apenas uma "anomalia europeia" (Luhmann, 1993, p. 586 [trad. esp., 2002, p. 664]). Esse é o paradoxo da sociedade mundial: a diferenciação funcional e autonomia dos sistemas irradiou-se do seu centro como exigência funcional e em certa medida como pretensão normativa, sendo quase que imposta (evidentemente de forma seletiva) às suas periferias, que não estiveram e não estão em condições de corresponder ou dispostas a adequar-se ao modelo da diferenciação. Isso decorre da imensa assimetria da sociedade mundial, insuscetível de ser considerada em um foco evolutivo simplificado.

Relacionado a isso, gostaria de enfatizar aqui que o modelo dominante de pluralismo constitucional parte de uma evolução linear da sociedade mundial que considera apenas o desenvolvimento do direito na modernidade central, na passagem do direito liberal (racionalidade formal),

${ }^{23}$ Cf. Teubner e Fischer-Lescano (2008) e Teubner (2012, pp. 242 e ss. [trad. ingl., 2012, pp. 162 e ss.]. 
passando pelo direito do Estado social (racionalidade material), para, com a crise deste, alcançar o direito reflexivo (Teubner, 2012, pp. 33 e ss. e pp. 45 e ss., espec. pp. 62-63 [trad. ingl., 2012, pp. 15 e ss., 24 e ss., espec. p. 35]) ${ }^{24}$. Da mesma maneira que já falamos acima em relação à questão da autonomia, o pluralismo constitucional dominante desconsidera que o Estado liberal, muito menos o Estado social, não se realizou na maioria dos contextos geográficos e demográficos de comunicação da sociedade moderna. Não se pode falar de crise do Estado social ou do Welfare State nesses contextos. Em muitas regiões do globo terrestre, os movimentos sociais demandam a presença de um mínimo de Estado social, sem o qual perde sentido falar em pluralismo jurídico "pós-moderno" ou global, senão como romantização pós-colonialista da miséria. Este é o paradoxo e também o equívoco decorrente do pluralismo jurídico na sociedade mundial: como se falar de inserção em redes 214 transacionais horizontais sem considerar as assimetrias gritantes e não apenas a nova "avalanche de exclusão" decorrente da desmontagem do Estado social (Luhmann, 2000, pp. 427-28), mas também a persistência de devastadora exclusão nas periferias da sociedade mundial? Além disso, como incluir na evolução linear de direito liberal (formal), direito do Estado social (material) e direito reflexivo, as formas tribais de ordens jurídicas não diferenciadas, que, antes de envolvidas na diferença inclusão/exclusão, envolvem o problema do isolamento/não isolamento?

O transconstitucionalismo leva a sério essas assimetrias na afirmação das pontes tanto contenciosas quanto cooperadoras de transição. Evidentemente, não se trata no transconstitucionalismo de "diálogos" constitucionais orientados para o entendimento entre cortes ou instância de ordens jurídicas diversas. Os problemas transconstitucionais impor-

${ }^{24}$ Ver também, em sua primeira formulação desse modelo, Teubner (1982, pp. 24-29). 
tam a dimensão contenciosa. E, mesmo quando se trata de "diálogo", este não deve ser entendido em termos de conciliação ou consenso, mas, antes, para referir a formas de comunicação destinadas à absorção do dissenso, assumindo a dupla contingência (Neves, 2009, pp. 270 e ss. [trad. ingl., 2013, pp. 169 e ss.]). Observe-se que a dupla contingência não diz respeito apenas às relações entre alter e ego enquanto pessoas na interação, mas refere-se também a sistemas (não apenas a sistemas organizacionais), na medida em que estes observam um ao outro reciprocamente, como bem salientou Luhmann, indo além do modelo de dupla contingência proposto pela teoria da ação (Luhmann, 1987 [1984], pp. 152 e 155 [trad. esp., 1998, pp. 115 e 117]). Entre diferentes ordens jurídicas, especialmente no plano dos problemas constitucionais, "diálogo" deve apontar para comunicação transversal, assentado na dupla contingência. "Diálogo", aqui, poderia ter um sentido análogo ao formulado por Feyerabend ${ }^{25}$, referindo-se a formas de comunicação orientadas para influenciar e modificar um ao outro reciprocamente, mostrando os limites das perspectivas correspondentes, sem que daí possa esperar-se algo como consenso. Mas, inclusive nesse sentido dissensual, a possiblidade de diálogo é apenas uma dimensão limitada do transconstitucionalismo entre ordens jurídicas. Talvez seja bem mais importante o aprendizado recíproco mediante o conflito, a contenda nas "pontes de transição". E tudo isso implica paradoxo decorrente da necessidade de surpreender-se permanentemente com o outro e sobre si mesmo.

A esse respeito, vou considerar nesta oportunidade apenas um caso que tratei em meu livro Transconstitucionalismo, em que o paradoxo transconstitucional é sobremaneira marcante.

25 "Ele pode mostrar o efeito de argumento sobre estranhos e sobre expertos de uma diferente escola", assim como "demonstrar que a natureza quimérica do que cremos são as partes mais sólidas de nossa vida" (Feyerabend, 1991, pp. 164-65). 


\section{Um caso emblemático: transconstitucionalismo entre ordem normativa de comunidade indígena e a ordem constitucional do Estado brasileiro}

O transconstitucionalismo envolve também a relação problemática entre as ordens jurídicas estatais e as ordens extraestatais de coletividades nativas, cujos pressupostos antropológico-culturais não se compatibilizam com o modelo de constitucionalismo do Estado. Evidentemente, nesse caso, trata-se de ordens "arcaicas" que não dispõem de princípios ou regras secundárias de organização e, por conseguinte, não se enquadram no modelo reflexivo do constitucionalismo. A rigor, elas não admitem problemas jurídico-constitucionais de direitos humanos e de limitação jurídica do poder. Ordens normativas dessa espécie exigem, quando entram em colisão com as instituições da ordem jurídica constitucional de um Estado, um "transconstitucionalismo unilateral" de tolerância e, em certa medida, de aprendiza-

216 do. Essa forma de transconstitucionalismo impõe-se porque - embora as referidas ordens jurídicas, em muitas de suas normas e práticas, afastem-se sensivelmente do modelo de direitos humanos e de limitação jurídica do poder nos termos do sistema jurídico da sociedade mundial - a simples imposição unilateral dos "direitos humanos" aos seus membros é contrária ao transconstitucionalismo. Medidas nessa direção tendem a ter consequências destrutivas sobre mentes e corpos, sendo contrárias ao próprio conceito de direitos humanos ${ }^{26}$. Nesse contexto, há um paradoxo do transconstitucionalismo, pois ele se envolve em "conversações" constitucionais com ordens normativas que estão à margem do próprio constitucionalismo. Mas essa situação é resultante da necessidade intrínseca ao transconstitucionalismo de

\footnotetext{
26 "A questão dos direitos humanos, no sentido rigoroso, deve ser compreendida hoje como ameaça à integridade de corpo/alma do homem individual por uma multiplicidade de processos de comunicação anônimos e independentes, atualmente globalizados" (Teubner, 2006, p. 180 [trad. ingl., 2006, p. 341]).
} 
não excluir o desenvolvimento de institutos alternativos que possibilitem um "diálogo" construtivo com essas ordens dos antropológico-culturalmente "diferentes", baseadas milenarmente no território do respectivo Estado. Portanto, nessas circunstâncias, embora limitado, o transconstitucionalismo não perde o seu significado para o desenvolvimento da dimensão normativa da sociedade mundial do presente.

A experiência latino-americana é rica de problemas jurídico-constitucionais decorrentes do entrelaçamento entre ordens normativas nativas e ordens constitucionais dos Estados, especialmente no que concerne aos direitos fundamentais.

Um dos casos mais delicados apresentou-se recentemente na relação entre a ordem jurídica estatal brasileira e a ordem normativa dos índios Suruahá, habitantes do município de Tapauá, localizado no estado do Amazonas, que permaneceram isolados voluntariamente até os fins da década de 1970 (Segato, 2011, p. 363). Conforme o direito consuetudinário dos Suruahá, é obrigatório o homicídio dos recém-nascidos quando tenham alguma deficiência física ou de saúde em geral. Em outra comunidade, a dos indígenas Yawanawá, localizada no estado do Acre, na fronteira entre Brasil e Peru, há uma ordem normativa consuetudinária que determina que se tire a vida de um dos gêmeos recém-nascidos. Nesse contexto, também se tornou público o fato de que práticas desse tipo eram comuns entre os Yanomami e outras etnias indígenas. Essa situação levou a polêmicas, pois se tratava de um conflito praticamente insolúvel entre direito de autonomia cultural e direito à vida. O problema já tomara destaque na ocasião em que uma indígena Yawanawá, em oficina de direitos humanos da Fundação Nacional do Índio, em 2002, descreveu a obrigatoriedade, em sua comunidade, da prática de homicídio de um dos gêmeos, apresentando-se como vítima dessa prática jurídica costumeira (Segato, 2011, pp. 357-58). Nesse 
contexto, a questão também foi apresentada como conflito entre direito de autonomia cultural e direito das mulheres. Passou, porém, a ter ampla repercussão pública em relação ao direito da criança à vida - sobretudo mediante a destacada difusão nos meios de comunicação de massa de grande influência - com a divulgação do resgate, por um casal de missionários, de uma criança com uma grave disfunção hormonal congênita, que estava condenada à morte entre os Suruahá27. Sobretudo a repercussão pública do costume dos Suruahá levou à proposição por parte do deputado federal Henrique Afonso, representante do estado do Acre, do Projeto de Lei $\mathrm{n}^{\circ} 1.057$, de 2007, destinado especificamente à criminalização dessa prática. A ementa desse projeto tinha originariamente o seguinte teor: "Dispõe sobre o combate a práticas tradicionais nocivas e à proteção dos direitos fundamentais de crianças indígenas, bem como pertencentes a outras sociedades ditas não tradicionais." ${ }^{28}$

218 Para fins de medidas específicas de combate a essas práticas, inclusive a criminalização daqueles que, em contato com a comunidade nativa, não fizessem a devida notificação às autoridades competentes, assim como das autoridades que não tomassem as providências cabíveis (artigos $3^{\circ}, 4^{\circ}$ e $5^{\circ}$ ), o artigo $2^{\circ}$, incisos I a VIII, do Projeto, previa a tipificação dos seguintes casos de "homicídio de recém-nascidos": "em casos de falta de um dos genitores"; "em casos de gestação múltipla"; "quando estes são portadores de doenças físicas e/ou mentais"; "quando há preferência de gênero"; "quando houver breve espaço de tempo entre uma gestação anterior e o nascimento em questão"; "em casos de exceder o número de filhos apropriado para o grupo"; "quando estes possuírem algum sinal ou marca de nascença que os diferencie dos demais"; "quando estes são considerados de má

\footnotetext{
${ }^{27}$ Cf. Segato (2011, p. 363).

${ }_{28}$ Disponível em: <http://www.camara.gov.br/proposicoesWeb/fichadetramitaca o? idProposicao=351362>. Acesso em: 17 dez. 2014.
} 
sorte para a família ou para o grupo". O Projeto originário também propunha a tipificação dos "homicídios de criança, em caso de crença de que a criança desnutrida é fruto de maldição, ou por qualquer outra crença que leve ao óbito intencional por desnutrição" (artigo 2º inciso IX). Essas hipóteses previstas no Projeto, além de outras referentes a abusos sexuais, maus tratos e outras agressões físico-psíquicas de crianças e seus genitores por fundamentos culturais e tradicionais (artigo $2^{\circ}$, incisos X, XI e XII), correspondem a práticas verificadas nas comunidades indígenas localizadas no território do Estado brasileiro. Esse Projeto deu ensejo a uma audiência pública na Comissão de Direitos Humanos da Câmara dos Deputados ${ }^{29}$. Embora não tenha logrado êxito, o contexto em que foi elaborado e a discussão que engendrou apontam para um caso singular de "diálogo" e colisão transconstitucional entre ordem jurídica estatal e ordens normativas locais das comunidades indígenas.

Os elaboradores e defensores do Projeto de Lei partiram primariamente da absolutização do direito fundamental individual à vida, nos termos da moral cristã ocidental. Secundariamente, também contribuiu para a proposição do Projeto o direito fundamental da mãe à maternidade. Essa postura

\footnotetext{
${ }^{29}$ Convocada pela Comissão de Direitos Humanos da Câmara dos Deputados em agosto de 2007 e realizada em 5 de setembro de 2007 (cf. Segato, 2011, pp. 357 e 369). Posteriormente, esse projeto de lei foi profundamente alterado, reduzindo-se a declarações genéricas e a previsão de apoio às respectivas comunidades, nos seguintes termos:

Art.54-A. Reafirma-se o respeito e o fomento às práticas tradicionais indígenas, sempre que as mesmas estejam em conformidade com os direitos fundamentais estabelecidos na Constituição Federal e com os tratados e convenções internacionais sobre direitos humanos de que a República Federativa do Brasil seja parte.

Parágrafo único. Cabe aos órgãos responsáveis pela política indigenista oferecerem oportunidades adequadas aos povos indígenas de adquirir conhecimentos sobre a sociedade em seu conjunto quando forem verificadas, mediante estudos antropológicos, as seguintes práticas:

I - infanticídio;

II - atentado violento ao pudor ou estupro;

III - maus tratos;

IV - agressões à integridade física e psíquica de crianças e seus genitores.
} 
unilateral pela imposição dos direitos individuais em detrimento da autonomia cultural das comunidades não pareceu adequada para os que se manifestaram em torno do problema em uma perspectiva antropológica mais abrangente. A simples criminalização das práticas indígenas, em nome da defesa do direito à vida, pode ser vista, outrossim, como um verdadeiro genocídio cultural, a destruição da própria comunidade, destruindo suas crenças mais profundas.

Com intensa participação no debate, inclusive na audiência pública realizada em 5 de setembro de 2007 na Câmara dos Deputados, as ponderações da antropóloga Rita Laura Segato contribuíram positivamente para o esclarecimento dessa colisão de ordens jurídicas, enfatizando a necessidade de um "diálogo" entre ordens normativas ${ }^{30}$, em termos que se enquadram em um modelo construtivo de transconstitucionalismo. No contexto do debate, Segato reconheceu que tinha diante de si "a tarefa ingrata de argumentar contra 220 essa lei, mas, ao mesmo tempo, de fazer uma forte aposta na transformação do costume" (Segato, 2011, p. 358). No âmbito de sua argumentação, ela invocou pesquisa empírica sobre os Suruahá, na qual se verificou que, em um grupo de 143 membros da comunidade indígena, entre 2003 e 2005, houve dezesseis nascimentos, 23 suicídios, dois homicídios de recém-nascidos (denominados pelos antropólogos "infanticídio”, sem o sentido técnico-jurídico do tipo penal) e uma morte por doença. Ou seja, enquanto 7,6\% das mortes ocorreram por "infanticídio", houve $57,6 \%$ de mortes por suicídio entre os Suruahá. Essa situação aponta uma compreensão da vida bem distinta da concepção cristã ocidental. Entre essa comunidade indígena, a vida só tem sentido se não for marcada por excessivo sofrimento para o indivíduo e a comunidade, se for uma vida tranquila e amena. Assim se justificaria o homicídio de recém-nascido em determina-

${ }^{30}$ Cf. Segato (2011, pp. 370 e ss.). 
dos casos (Segato, 2011, pp. 364-65). O significado atribuído à vida e à morte pelos Suruahá não seria menos digno do que o sentido que lhes atribui o cristianismo: "Também constatamos que se trata de uma visão complexa, sofisticada e de grande dignidade filosófica, que nada deve aos cristianismos" (Segato, 2011, p. 364).

$\mathrm{O}$ argumento é fortificado com a referência à prática yanomami, na qual a mulher tem direito absoluto sobre a vida dos seus recém-nascidos. O parto ocorre em ambiente natural, fora do contexto da vida social, deixando a opção à mãe:

[...] se não toca o bebê nem o levanta em seus braços, deixando-o na terra onde caiu, significa que este não foi acolhido no mundo da cultura e das relações sociais, e que não é, portanto, humano. Dessa forma, não se pode dizer que ocorreu, na perspectiva nativa, um homicídio, pois aquele que permaneceu na terra não é uma vida humana (Segato, 2011, p. 365).

Essa concepção bem diversa da vida humana importa realmente um delicado problema que - parece-me - é incompatível com uma mera imposição de concepções externas sobre a vida e a morte, mediante aquilo que, em outro contexto, chamei paradoxalmente de "imperialismo dos direitos humanos" (Neves, 2005, pp. 23 e 27). E isso é válido não apenas de um ponto de vista antropológico-cultural ou antropológico-jurídico, mas também na perspectiva específica de um direito constitucional sensível ao transconstitucionalismo.

Impõe-se nesse contexto considerar a colisão entre duas perspectivas diversas dos direitos, procurando não "fazer injustiça" mediante a imposição de uma, a da ordem dos mais fortes, à outra, a da ordem dos mais fracos. De um lado está o direito à autonomia coletiva, do outro o direito à autonomia individual. Simplesmente submeter aquele, considera- 
do expressão de uma forma ética de vida, a este, considerado expressão de uma moral universal que se apresenta como base dos direitos humanos ${ }^{31}$, não parece a solução mais oportuna em um modelo de transconstitucionalismo. Ao contrário, nesse contexto de colisão radical entre a ordem jurídica estatal e as ordens normativas indígenas, tem-se de considerar e ponderar entre "o direito à vida do sujeito individual e o direito à vida do sujeito coletivo", como argui Segato (2011, p. 367) 32. No caso, a "ultracriminalização" das práticas do homicídio de recém-nascidos praticadas no interior das comunidades indígenas, proposta na versão original do Projeto de Lei $\mathrm{n}^{\circ} 1.057$, de 2007, poderia ser "etnocida, ao eliminar valores culturais indispensáveis à vida biológica e cultural de um povo" (Botero, 2006, p. 156; também citada por Segato, 2011, p. 367). Assim sendo, tal solução legal teria implicações de difícil compatibilização inclusive com a ordem constitucional do Estado brasileiro ${ }^{33}$. Parece ser necessária, nessas 222 circunstâncias, a busca de outros caminhos.

A proposta que se afigura mais adequada ao transconstitucionalismo reside em garantir a "jurisdição ou foro étnico",

${ }^{31}$ Klaus Günther (1988, p. 196 [trad. ingl., 1993, p. 153]), embora sustente que "a aplicação adequada de normas jurídicas não pode, sem fundamento, ofender formas de vida" (grifo meu), mostra-se antes favorável a uma tal orientação, quando sustenta que "as colisões entre princípios de justiça e orientações da vida boa, no nível pós-convencional, só podem ser resolvidas universalistamente, portanto, em favor da justiça”. Cabe advertir, porém, que nos termos da teoria habermasiana da ação comunicativa e do discurso, segundo a qual Günther se orienta, haveria, no caso, a colisão entre uma moral pós-convencional e uma pré-convencional. Sobre os níveis do desenvolvimento da consciência moral na teoria da evolução social de Habermas, ver Neves (2006, pp. 25 e ss.).

32 A respeito, afirmou Segato na referida audiência pública, referindo-se "ao significado da expressão 'direito à vida" nesse contexto: "Essa expressão pode indicar dois tipos diferentes de direito à vida: o direito individual à vida, quer dizer, a proteção do sujeito individual de direitos, e o direito à vida dos sujeitos coletivos, isto é, o direito à proteção da vida dos povos em sua condição de povos" (Segato, 2011, p. 372).

${ }^{33}$ E especificamente por força do disposto no art. 231, caput, da Constituição Federal: "São reconhecidos aos índios sua organização social, costumes, línguas, crenças e tradições, e os direitos originários sobre as terras que tradicionalmente ocupam, competindo à União demarcá-las, proteger e fazer respeitar todos os seus bens". 
para que cada comunidade indígena "resolva seus conflitos e elabore seu dissenso interno por um caminho próprio" (Segato, 2011, pp. 375 e 377). Isso não implica simplesmente tolerância do mais poderoso, tampouco tolerância perante o intolerante (Rawls, 1990 [1972], pp. 216-21), antes se trata de capacidade de admitir a autonomia do outro, isto é, da esfera de comunicação, do jogo de linguagem ou da forma de vida diferente do nativo, não submetida aos modelos do constitucionalismo estatal. Muito menos cabe falar de sociedades "decentes" e "indecentes", ou seja, dignas ou indignas do "diálogo" com as sociedades "liberais" do Estado democrático constitucional (Rawls, 1999, pp. 4-5 e 59 e ss.), como se não estivéssemos na mesma sociedade mundial, com colisões e conflitos entre domínios de comunicação e jogos de linguagem. Mas cabe ponderar que, não só de um ponto de vista antropológico, mas também na perspectiva do transconstitucionalismo, diante dos dissensos e conflitos no interior das comunidades indígenas, inclusive em torno da prática do homicídio de recém-nascidos, "o papel do Estado, na pessoa dos seus agentes, terá de ser o de estar disponível para supervisionar, mediar ou interceder com o fim único de garantir que o processo interno de deliberação possa ocorrer livremente, sem abuso por parte dos mais poderosos no interior da sociedade" (Segato, 2011, p. 375) ${ }^{34}$. Assim, neste contexto, a postura transconstitucional apresenta-se na limitação jurídica do poder abusivo dentro da comunidade. Isso porque, caso haja manipulação das decisões comunitárias pelos mais poderosos,

\footnotetext{
${ }^{34}$ A esse respeito, acrescenta Segato (2011, pp. 375-76): "Tampouco se trata de solicitar a retirada do Estado, porque, como atestam as múltiplas demandas por políticas públicas colocadas perante o mesmo pelos povos indígenas a partir da Constituição de 1988, depois da intensa e perniciosa desordem instalada pelo contato, o Estado já não pode, simplesmente, ausentar-se. Deve permanecer disponível para oferecer garantias e proteção quando convocado por membros das comunidades, sempre que essa intervenção ocorra em diálogo entre os representantes do Estado e os representantes da comunidade em questão. Seu papel, nesse caso, não poderá ser outro, a não ser o de promover e facilitar o diálogo entre os poderes da aldeia e seus membros mais frágeis".
} 
sem legitimidade na ordem normativa respectiva, desaparece a autonomia étnica de que se parte para o "diálogo" constitucional. Portanto, observa-se, dessa maneira, que nenhuma forma de apresentação de autonomia de esferas sociais, inclusive das construídas por comunidades nativas não diferenciadas funcionalmente, tem um caráter absoluto, sendo todas relativas no âmbito da sociedade mundial do presente.

Esse delicado problema não se restringe ao dilema entre relativismo ético (das culturas particulares) e universalismo moral (dos direitos dos homens), antes aponta para o convívio de ordens jurídicas que partem de experiências históricas diversas ${ }^{35}$, exigindo especialmente por parte do Estado constitucional uma postura de moderação relativamente à sua pretensão de concretizar suas normas específicas, quando essas entrem em colisão com normas de comunidades nativas fundadas em bases culturais essencialmente diferentes. A discrição e o comedimento, nesse caso, 224 parecem ser a via que pode levar a conversações construtivas que estimulem autotransformações internas das comunidades indígenas para uma relação menos conflituosa com a ordem estatal. A tentativa de buscar modelos internos de otimização, nos termos da teoria dos princípios, pode ser desastrosa nessas circunstâncias. Em relação ao "outro", à ordem diversa dos nativos, cabe antes uma postura transconstitucional de autocontenção dos direitos fundamentais cuja otimização possa levar à desintegração de formas de vida, com consequências destrutivas para os corpos e as mentes dos membros das respectivas comunidades ${ }^{36}$.

Mas esse problema não se restringe à relação das ordens jurídicas consuetudinárias das comunidades indígenas com a ordem jurídica estatal, envolvendo também a ordem inter-

35 Cf. Segato (2011, pp. 375-77); ver, de maneira mais abrangente, Segato (2006, pp. 207-36). A respeito da relação intrínseca entre universalismo e diferença, ver Neves (2001).

${ }^{36}$ Ver supra nota 25. 
nacional. Há, então, um entrelaçamentos pluridimensional em torno de direitos humanos. A respeito, é relevante a Convenção 169 da Organização Internacional do Trabalho (OIT) sobre Povos Indígenas e Tribais ${ }^{37}$, cujo art. $8^{\circ}, \mathrm{n}^{\circ} 2$, prescreve: "Esses povos deverão ter o direito de conservar seus costumes e instituições próprias, desde que eles não sejam incompatíveis com os direitos fundamentais definidos pelo sistema jurídico nacional nem com os direitos humanos internacionalmente reconhecidos [...]." Esse preceito torna mais complicada a colisão das ordens locais nativas com a ordem dos direitos fundamentais estatais e dos direitos humanos internacionais. Uma interpretação literal desse dispositivo, em nome da proteção absoluta da vida dos recém-nascidos, levaria tendencialmente a um etnocídio contra as respectivas comunidades indígenas. Parece-me que os argumentos apresentados no item anterior não perdem o seu significado em virtude dessa referência ao direito internacional. Nesses casos, cabe não apenas uma releitura complexamente adequada tanto das normas estatais de direitos fundamentais quanto das normas internacionais de direitos humanos. Um universalismo superficial dos direitos humanos, baseado linearmente em uma certa concepção ocidental ontológica de tais direitos, é incompatível com um "diálogo" transconstitucional com ordens nativas que não correspondem a esse modelo. Ao contrário, a negação de uma comunicação transversal com ordens indígenas em torno dessas questões delicadas é contrária aos próprios direitos humanos, pois implicaria uma "ultracriminalização" de toda a comunidade de autores e coautores dos respectivos atos, afetando-lhes indiscriminadamente corpo e mente mediante uma ingerência destrutiva. No âmbito de um transconstitucionalismo positivo impõe-se, nesses casos,

37 A respeito dessa Convenção, ver a breve exposição de Wolfrum (1999 [trad. bras., 2008]). 
uma disposição das ordens estatais e internacionais de surpreender-se em um aprendizado recíproco com a experiência do outro, o nativo em sua autocompreensão.

Uma transformação profunda tem ocorrido, nas condições hodiernas da sociedade mundial, no sentido da superação do constitucionalismo provinciano ou paroquial pelo transconstitucionalismo. Essa transformação deve ser levada a sério. O Estado deixou de ser um locus privilegiado de solução de problemas constitucionais. Embora fundamental e indispensável, é apenas um dos diversos loci em cooperação e concorrência na busca do tratamento desses problemas. A integração sistêmica cada vez maior da sociedade mundial levou à desterritorialização de problemas-caso jurídico-constitucionais, que, por assim dizer, eman226 ciparam-se do Estado. Essa situação não deve levar, porém, a novas ilusões, na busca de "níveis invioláveis" definitivos: internacionalismo como ultima ratio, conforme uma nova hierarquização absoluta; supranacionalismo como panaceia jurídica; transnacionalismo como fragmentação libertadora das amarras do Estado; localismo como expressão de uma etnicidade definitivamente inviolável ${ }^{38}$.

Contra essas tendências, o transconstitucionalismo implica o reconhecimento de que as diversas ordens jurídicas entrelaçadas na solução de um problema-caso constitucional - a saber, de direitos fundamentais ou humanos e de organização legítima do poder -, que lhes seja concomitantemente relevante, devem buscar formas transversais de articulação para a solução do problema, cada uma delas observando a outra, para compreender os seus próprios

\footnotetext{
38 O "nível inviolável" pode envolver-se, no dinâmico jogo transconstitucional, com outros níveis (entrelaçados) em um "nível superentrelaçado", nos termos de Hofstadter (1979, pp. 686 e ss. [trad. bras., 2001, pp. 753 e ss.]).
} 
limites e possibilidades de contribuir para solucioná-lo. Sua identidade é reconstruída, dessa maneira, enquanto leva a sério a alteridade, a observação do outro. Isso me parece frutífero e enriquecedor da própria identidade porque todo observador tem um limite de visão no "ponto cego", aquele que o observador não pode ver em virtude da sua posição ou perspectiva de observação (Von Foerster, 1981, pp. 288-89). Mas, se é verdade, considerando a diversidade de perspectivas de observação de alter e ego, que "eu vejo o que tu não vês" (Luhmann, 1990b), cabe acrescentar que o "ponto cego" de um observador pode ser visto pelo outro. Nesse sentido, pode-se afirmar que o transconstitucionalismo implica o reconhecimento dos limites de observação de uma determinada ordem, que admite a alternativa: $o$ ponto cego, o outro pode ver.

\section{Marcelo Neves}

é professor de Direito Público da Faculdade de Direito da Universidade de Brasília (UnB).

\section{Bibliografia}

ACKERMAN, B. 1997. "The rise of world constitutionalism". Virginia Law Review, 83, pp. 771-97. Charlottesville/VA: Virginia Law Review Association. [trad. bras.: "A ascensão do constitucionalismo mundial". In: SOUZA NETO, C. P.; SARMENTO, D. (orgs.). A constitucionalização do direito: fundamentos teóricos e aplicações específicas. Rio de Janeiro: Lumen Juris, 2007, pp. 89-111].

ATLAN, H. 1979. Entre le cristal et la fumée: essai sur l'organisation du vivant. Paris: Seuil.

BERMAN, H. J. 1983. Law and revolution: the formation of the western legal tradition. Cambridge, MA/London: Harvard University Press [trad. bras.: Direito e revolução: a formação da tradição jurídica ocidental. São Leopoldo, RS: Unisinos, 2006].

BIAGGINI, G. 2000. "Die Idee der Verfassung - Neuausrichtung im Zeitalter der Globalisierung?”. Zeitschrift für Schweizerisches Recht, n. 141 (119 da nova série), pp. 445-76. Basel/München: Helbing \& Lichtenhahn. 
BOTERO, E. S. 2006. Entre el juez Salomón y el Dios Sira. Decisiones interculturales e interés superior del niño. Bogotá: Universidad de Amsterdam y Unicef.

BURDEAU, G. 1949. Traité de science politique. 2. ed. Paris: Librairie Générale de Droit et de Jurisprudence, v. I.

CANOTILHO, J. J. G. 1991. Direito constitucional. 5. ed. Coimbra: Almedina. . 2006. "Brancosos" e interconstitucionalidade: itinerários dos discursos sobre a historicidade constitucional. Coimbra: Almedina.

CARROLL, L.1939 [1872]. Through the looking-glass and what Alice found there. The complete works of Lewis Carroll. London/ New York: The Nonesuch Press/ Random House, pp. 133-272.

DARWIN, C. 1971. The origin of species. London: J. M. Dent \& Sons.

ENGELS, F. 1988. "Die Lage Englands. II. Die englische Konstitution”. In: MARX, K.; ENGELS; F. Werke. 15. ed. Berlim: Dietz Verlag, v. I, pp. 56992 [originalmente em: Vorwärts!, n. 75, de 18 set. 1844].

FASSBENDER, B. 1998. "The United Nations Charter as Constitution of the International Community". Columbia Journal of Transnational Law, v. 36, n. 3, pp. 529-619. New York: The Columbia Journal of Transnational Law Association.

FEYERABEND, P. K. 1991. Three dialogues on knowledge. Oxford: Basil Blackwell.

FISCHER-LESCANO, A. 2005. Globalverfassung: die Geltungsbegründung der Menschenrechte. Weilerswist: Velbrück.

FISCHER-LESCANO, A.; TEUBNER, G. 2006. Regime-Kollisionen: Zur

Fragmentierung des globalen Rechts. Frankfurt am Main: Suhrkamp. . 2007. "Fragmentierung des Weltrechts: Vernetzung globaler

Regimes statt etatischer Rechtseinheit”. In: ALBERT, M.; STICHWEH, R. (orgs.). Weltstaat und Weltstaatlichkeit: beobachtungen globaler politischer Strukturbildung. Wiesbaden: VS Verlag, pp. 37-61.

GROSS, O. 2006. “'Control systems' and the migration of anomalies”. In:

CHOUDHRY, S. (org.). The migration of constitutional ideas. Cambridge: Cambridge University Press, pp. 403-30.

GÜNTHER, K. 1988. Der Sinn fürAngemessenheit: Anwendungsdiskurse in Moral und Recht. Frankfurt am Main: Suhrkamp [trad. ingl., 1993. Law as an autopoietic system. Oxford/Cambridge, MA: Blackwell].

HALDANE, J. B. S. 1990. "Disease and evolution". In: DRONAMRAJU, K. R. (org.). Selected genetic papers of J. B. S. Haldane. New York/London: Garland, pp. 325-34 [publicado originalmente em: La Ricerca Scientifica, Supplemento, ano 19, 1949, pp. 2-11].

HAMILTON, W. D. 1980. "Sex versus non-sex versus parasite". Oikos, n. 35, pp. 282-90. Hoboken, NJ: Wiley-Blackwell/Copenhague: Nordic Society Oikos. 
HAMILTON, W. D.; AXELROD, R.; TANESE, R. 1990. "Sexual reproduction as an adaptation to resist parasites (A Review)". Proceedings of the National Academy of Sciences of the United States of America, v. 87, n. 9, pp. 3566-73.

HAMILTON, W. D.; HENDERSON, P. A.; MORAN, N. A. 1981.

"Fluctuation of environment and coevolved antagonist polymorphism as factors in the maintenance of sex". In: ALEXANDER, R.; TINKLE, D. W. (orgs.). Natural selection and social behaviour. recent research and new theory. New York: Chiron Press, pp. 363-81.

HART, H. L. A. 1994 [1961]. The concept of law. 2. ed. Oxford: Clarendon Press [trad. port.: 2001. O conceito de direito. 3 ed. Lisboa: Fundação Calouste Gulbenkian].

HELLER, H. 1934. Staatslehre. Leiden: A. W. Sijthoff [trad. bras.: Teoria do Estado. São Paulo: Mestre Jou, 1968].

HESPANHA, A. M. 2004. Guiando a mão invisível: direito, Estado e lei no liberalismo monárquico português. Coimbra: Almedina.

HOFSTADTER, D. 1979. Gödel, Escher, Bach: an Eternal Golden Braid. Hassocks: The Harvester Press [trad. bras.: 2001. Gödel, Escher, Bach: um entrelaçamento de gênios brilhantes. Brasília/São Paulo: UnB/ Imprensa Oficial].

KELSEN, H. 1925. Allgemeine Staatslehre. Bad Hamburg v. d. Höhe/Berlin/ Zurich: Gehlen [reimpressão inalterada: 1966]. . 1946. General theory of law and State. Trad. ingl. A. Wedberg. Cambridge, MA: Harvard University Press [trad. bras.: 2005. Teoria geral do direito e do Estado. 4.ed. São Paulo: Martins Fontes].

.1960. Reine Rechtslehre. 2. ed. Wien: Franz Deuticke [reimpressão inalterada: 1983] [trad. bras.: 2006. Teoria pura do direito. 7. ed. São Paulo: Martins Fontes].

KOSELLECK, R. 2006. "Begriffsgeschichtliche Probleme der Verfassungsgeschichtsbeschreibung”. In: KOSELLECK, R. Begriffsgeschichten. Frankfurt am Main: Suhrkamp, pp. 365-401.

LASSALLE, F. 1987. "Über Verfassungswesen” [1962]. In: FRIEDERICI, H. J. (org.). Reden und Schriften. Köln: Röderberg, pp. 120-47. [trad. bras.: 1980. Que é uma Constituição? Porto Alegre: Editorial Villa Martha].

LUHMANN, N. 1987. Soziale Systeme: Grundriss einer allgemeinen Theorie [1984]. Frankfurt am Main: Suhrkamp [trad. esp.: 1998. Sistemas sociales: lineamientos para una teoría general. 2. ed. Barcelona/ México/Santafé de Bogotá: Anthropos/Universidad Iberoamericana/ CEJA]. . 1990a. "Verfassung als evolutionäre Errungenschaft". Rechtshistorisches Journal, n. 9, pp. 176-220. Frankfurt am Main: Löwenklau. 
1990b. "Ich sehe was, was Du nicht siehst". In: LUHMANN, N.

Soziologische Aufklärung 5: Konstruktivistische Perspektiven, pp. 228-34.

Opladen: Westdeutscher Verlag.

1993. Das Recht der Gesellschaft. Frankfurt am Main: Suhrkamp

[trad. esp.: 2002. El derecho de la sociedad. México: Universidad

Iberoamericana].

2000. Die Politik der Gesellschaft. Frankfurt am Main: Suhrkamp.

MADURO, M. P. 2006. A Constituição plural: constitucionalismo e União

Europeia. Cascais: Principia.

MATURANA, H. R.; VARELA, F. J. 1980. Autopoiesis and cognition: the realization of the living. Dordrecht: D. Reidel.

1987. Der Baum der Erkenntnis: die biologischen Wurzeln des

menschlichen Erkennens. Trad. alemã de Kurt Ludewig. 3. ed. Bern/

München/Wien: Scherz.

MEIRMANS, S. 2009. "The evolution of the problem of sex". In: SCHÖN,

I.; MARTENS, K.; DIJK, P. van (eds.). Lost sex: the evolutionary biology

of parthenogenesis. Dordrecht/Heidelberg/London/New York:

Springer, pp. 21-46.

NEIMAN, M.; KOSKELLA, B. 2009. "Sex and Red Queen”. In: SCHÖN, I.;

MARTENS, K.; DIJK, P. van (eds.). Lost sex: the evolutionary biology of

230 parthenogenesis. Dordrecht/Heidelberg/London/New York: Springer, pp. 133-59.

NEVES, M. 2001. "Justicia y diferencia en una sociedad global compleja".

Doxa - Cuadernos de Filosofía del Derecho, n. 24, pp. 349-77. Alicante:

Universidad de Alicante.

. 2005. "A força simbólica dos direitos humanos". Revista Eletrônica de

Direito do Estado, n. 4. Salvador: Instituto de Direito Público da Bahia. 2006. Entre Têmis e Leviatã: uma relação difícil - o Estado

democrático de direito a partir e além de Luhmann e Habermas. São

Paulo: Martins Fontes.

. 2009. Transconstitucionalismo. São Paulo: WMF Martins Fontes [trad.

ingl.: 2013. Transconstitutionalism. Oxford: Hart].

PERNICE, I. 1999. "Multilevel constitutionalism and treaty of Amsterdam:

European constitution-making revisited?”. Common Market Law Review,

v. 36, n. 4, pp. 703-50. Alphen aan den Rijn: Kluwer Law International.

2002. "Multilevel constitutionalism in the European Union".

European Law Review, 27, pp. 511-29. Andover: Sweet \& Maxwell.

PIRES, F. 1997. Introdução ao direito constitucional europeu (seu sentido,

problemas e limites). Coimbra: Almedina.

RAWLS, J. 1972. A theory of justice. Oxford: Oxford University Press. 
1999. The law of peoples, with "The idea of public reason revisited".

Cambridge, MA/London: Harvard University Press.

RIDDLEY, M. 2003.The Red Queen: sex and evolution of human nature.

New York: Harper Collins.

ROACH, K. 2006. "The post-9/11 migration of Britain's Terrorism Act 2000". In: CHOUDHRY, S. (org.). The migration of constitutional ideas. Cambridge: Cambridge University Press, pp. 373-402.

SCHEPPELE, K. L. 2006. "The migration of anti-constitutional ideas: the post-9/11 globalization of public law and the international state of emergency”. In: CHOUDHRY, S (org.). The migration of constitutional ideas. Cambridge: Cambridge University Press, pp. 347-73.

SEGATO, R. L. 2006. "Antropologia e direitos humanos: alteridade e ética no movimento de expansão dos direitos universais”. Mana: Estudos de Antropologia Social, v. 12, n. 1, Rio de Janeiro, PPGAS-Museu Nacional/ UFRJ, pp. 207-36.

2011. "Que cada pueblo teja los hilos de su historia. El pluralismo jurídico en diálogo didáctico con legisladores”. In: CHENAUT, V.; GÓMEZ, M.; ORTIZ, H.; SIERRA, M. T. (orgs.). Justicia y diversidad en América Latina. Pueblos indígenas ante la globalización. México/Quito: CIESAS/FLACSO, pp. 357-81.

SMEND, R. 1968. "Verfassung und Verfassungsrecht (1928)". In: SMEND,

R.. Staatsrechtliche Abhandlungen und andere Aufsätze. 2. ed. Berlin:

Duncker \& Humblot, pp. 119-276.

TEUBNER, G. 1982. "Reflexives Recht: Entwicklungsmodelle des Rechts in vergleichender Perspektive". Archiv für Rechts- und Sozialphilosophie, n. 68. Wiesbaden: Steiner, pp. 13-59. 1989. Recht als autopoietisches System. Frankfurt am Main: Suhrkamp [trad. port.: 1993. O direito como sistema autopoiético. Lisboa: Fundação Calouste Gulbenkian]. . 2003. "Globale Zivilverfassungen: Alternativen zur staatszentrierten Verfassungstheorie”. Zeitschrift für ausländisches öffentliches Recht und Völkerrecht v. 63, n. 1, pp. 1-28. Heidelberg: Max Planck Institut für ausländisches öffentliches Recht und Völkerrecht.

. 2006. "Die AnonymeMatrix: ZuMenschenrechtsverletzungendurch 'private' transnationaleAkteure”. Der Staat, v. 45, n. 2, pp. 161-87.

Berlin: Duncker und Humblot. 2012 Verfassungsfragmente: gesellschaftlicher Konstitutionalismus in der Globalisierung. Berlin: Suhrkamp [trad. ingl.: 2012. Constitutional fragments: societal constitutionalism and globalisation. Oxford: Oxford University Press]. 
TEUBNER, G.; FISCHER-LESCANO, A. 2008. "Cannibalizing epistemes: will modern law protect traditional cultural expressions?”. In: GRABER, C. B.; BURRI-NENOVA, M. (orgs.). Traditional cultural expressions in a digital environment. Cheltenham: Edward Elgar, pp. 17-45.

THORNHILL, C. 2011. A sociology of constitutions. Constitutions and State legitimacy in historical-sociological perspective. Cambridge: Cambridge University Press.

TOMUSCHAT, C. 1995. "Die internationale Gemeinschaft". Archiv des Völkerrechts, n. 33, pp. 1-20. Tübingen: Mohr.

TUSHNET, M. 2008. "The inevitable globalization of constitutional law". Paper apresentado no seminário The Changing Role of Highest Courts in an Internationalizing World, promovido pelo Hague Institute for the Internationalisation of Law, 23 a 24 de outubro. Disponível em: <http:/ /ssrn.com/abstract=1317766>. Acesso em: 16 dez. 2014.

VAN VALEN, L. 1974. "Molecular evolution as predicted by natural selection”. Journal of Molecular Evolution, v. 3, n. 2, pp. 89-101. New York: Springer.

VON FOERSTER, H. 1981. "On constructing reality". In: VON FOERSTER, H. Observing systems. Seaside: Intersystems Publications, pp. 288-309.

232 WEBER, M. 1985 [1922]. Wirtschaft und Gesellschaft: Grundriß der verstehenden Soziologie. 5. ed. Org. Johannes Winckelmann. Tübingen: Mohr [trad. bras.: 2004. Economia e sociedade: fundamentos da sociologia compreensiva. Brasília/São Paulo: UnB/ Imprensa Oficial, 2 v.].

WEILER, J. 1999. The Constitution of Europe: "Do the new clothes have an emperor?" and other essays on European integration. Cambridge: Cambridge University Press.

WELSCH, W. 1996. Vernunft: die zeitgenössische Vernunftkritik und das Konzept der transversalen Vernunft. 2. ed. Frankfurt am Main: Suhrkamp. 2002. Unsere postmoderne Moderne. 6. ed. Berlin: Akademie Verlag.

WOLFRUM, R. 1999. "The protection of indigenous peoples in international law”. Zeitschrift für ausländisches öffentliches Recht und Völkerrecht, n. 59, pp. 369-82. Stuttgart: Verlag W. Kohlhammer/ Heidelberg: Max-Planck-Institut für Völkerrecht [trad. bras.: 2008. "A proteção dos povos indígenas no direito internacional". In: SARMENTO, D.; IKAWA, D.; PIOVESAN, F. (orgs.). Igualdade, diferença e direitos humanos. Rio de Janeiro: Lumen Juris, pp. 599-614]. 


\section{(NÃO) SOLUCIONANDO PROBLEMAS CONSTITUCIONAIS: TRANSCONSTITUCIONALISMO ALÉM DE COLISÕES}

MARCELO NEVES

Resumo: $\mathrm{O}$ artigo discute criticamente o modelo de colisão entre regimes jurídicos e constitucionais à luz da concepção de transconstitucionalismo. Em um primeiro momento, o autor procura afastar-se da ideia em voga de que teria ocorrido a emergência de uma multidão de novas constituições, conforme um uso inflacionário do termo "constituição". Em um segundo passo, o artigo faz uma crítica ao modelo de fragmentação de regimes jurídicos e constitucionais, tal como proposto por Gunther Teubner, para apontar a necessidade de tessitura dos fragmentos, na perspectiva de uma razão transversal. Em seguida, o autor expõe o problema transconstitucional do homicídio de crianças recém-nascidas com deficiências, entre os índios Suruahá e outros grupos indígenas, para colocar o paradoxo do transconstitucionalismo além de um modelo ocidentalista e simplesmente cosmopolita de constitucionalismo global. Na observação final, o autor aponta para um caminho que vai além de reconhecer que todo observador tem um ponto cego, para enfatizar uma perspectiva de alteridade em que o ponto de cego de um pode ser visto por um outro, em uma conexão transversal de dupla contingência.

Palavras-chave: Constituição; Constitucionalismo além do Estado; Colisões de Regimes; Teoria dos Sistemas; Transconstitucionalismo.

\section{(NOT) SOLVING CONSTITUTIONAL PROBLEMS: TRANSCONSTITUTIONALISM BEYOND COLLISIONS}

Abstract: The paper critically discusses the theorical model that emphasizes the collision between legal and constitutional regimes in the light of the theory of transconstitutionalism. At first, the 
author takes distance from the currently widespread idea that there has been the emergence of a multitude of new constitutions according to an inflationary use of the term "constitution". In a second step, the paper develops a critical approach on the model of fragmentation of legal and constitutional regimes, as proposed by Gunther Teubner, in order to point out the need for weaving of fragments in the perspective a transversal rationality. Then, the author exposes the transconstitutional problem concerning the murder of newborn children with disabilities, among Suruawa Indians and other indigenous groups to approach the paradox transconstitutionalism beyond a westerner and simply cosmopolitan global constitutionalism model. In the final observation, the author points to a path that goes beyond recognizing that every observer has a blind spot to emphasize to gain a perspective of alterity in which a blind point can be seen by another in a transversal connection of double contingency.

Keywords: Constitution; Constitutionalism beyond the State; Regimes Collisions; Theory Systems; Transconstitutionalism. 